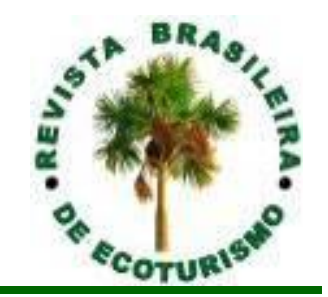

\title{
Percepção sobre serviços ecossistêmicos e áreas protegidas em uma microbacia com interface urbano-rural (Boituva, SP)
}

\section{Perception about ecosystem services and protected areas in a watershed with urban-rural interface (Boituva, SP, Brazil)}

\author{
Giovana Francesca Rodrigues Consorti, Gabriel Telo Mariano, \\ Helbert Medeiros Prado, Eliana Cardoso-Leite
}

RESUMO: Os serviços ecossistêmicos são essenciais para a vida humana e podem ser potencializados com a criação de áreas protegidas, seja no contexto rural ou urbano. Este estudo teve como objetivo analisar a percepção dos moradores da Bacia do Ribeirão Pau D'Alho, em Boituva/SP, Brasil, acerca das áreas naturais de seu entorno e da possibilidade de criação de novas Unidades de Conservação (UC). Foi dada ênfase especial às comparações entre moradores rurais e àqueles no contexto urbano. Nesta bacia, uma área de alta prioridade para a conservação, existe um parque denominado "Parque Ecológico Eugênio Walter", que não é coberto pelo 'SNUC' (Lei Brasileira de Unidades de Conservação), ou seja, não é uma área protegida por lei. Fazendo uso de entrevistas semiestruturadas, 18 moradores rurais e 19 moradores urbanos participaram da pesquisa, com idades variando de 18 a 87 anos, em sua maioria com ensino médio. A partir da fala dos entrevistados, metáforas foram identificadas e classificadas enquanto representativas dos diferentes serviços ecossistêmicos, conforme modelos analíticos da relação Homem-natureza presente na literatura. Os resultados indicaram que não houve diferença significativa entre as percepções de moradores urbanos e rurais ao considerarem positiva a existência de áreas naturais em seu entorno. Os serviços ecossistêmicos culturais, atrelados ao sentimento de bem-estar que a natureza promove, foram os mais citados na percepção dos entrevistados em ambos os grupos de moradores. O serviço ecossistêmico de Regulação foi o segundo mais citado, estando, principalmente, relacionado ao clima e à qualidade do ar. Em termos gerais, a população entrevistada concorda com a criação de Unidade de Conservação na região e anseia por locais de lazer e contato com a natureza. $O$ fato de Boituva ser um município de interesse turístico pode explicar parte dos dados obtidos. Por fim, os resultados aqui podem orientar a implementação de políticas públicas, voltadas à criação de novas áreas protegidas na região da microbacia foco deste estudo.

PALAVRAS-CHAVE: Metáforas; Bem-estar; Conservação; Áreas Verdes Urbanas; Parque Natural Municipal. 
ABSTRACT: Ecosystem services are essential to human life and can be enhanced and potentialized with the creation of protected areas, either in the rural or urban context. Based on a study carried out in Boituva / SP, this study aimed to analyze the perception of residents of the Ribeirão Pau D'Alho basin, about the natural areas in its surroundings and the possibility of creating new Protected Areas. Special emphasis was given to comparisons between rural residents and those in the urban context. In this watershed, a high priority area for conservation, there is a park called "Parque Ecológico Eugênio Walter", which is not covered by the 'SNUC' (Brazilian Law of Conservation Units), in other words, it isn't a Protected Area. Using semi-structured interviews, 18 rural and 19 urban dwellers participated in the research, with ages ranging from 18 to 87 years old, most of whom had attended high school. From the interviewees' speech, metaphors were identified and classified as representative of the different ecosystem services, according to analytical models of the human-nature relationship present in the literature. The results indicated that there was no significant difference between the perceptions of urban and rural dwellers when considering the existence of natural areas in their surroundings as positive. The cultural ecosystem services, linked to the feeling of well-being that nature promotes, were the most evident in the perception of the respondents in both groups of residents. The Regulating ecosystem service was the second most prominent, being mainly related to climate and air quality in the participants' speech. In general terms, the interviewed population agrees with the creation of a Protected Area in the region and longs for places of leisure and contact with nature. The fact that the city Boituva aspect of being a Municipality of Tourist Interest may explain part of the data obtained. Finally, the results here can guide the implementation of public policies, aimed at the creation of new protected areas in the watershed region focused on this study.

KEYWORDS: Metaphors; Well-Being; Conservation; Urban Green Areas; Municipal Natural Park.

\section{Introdução}

A História de progresso material das sociedades humanas, em especial a partir da revolução industrial tem provocado a degradação, exaustão e insustentabilidade ambiental, resultando em mudanças globais e permanentes no regime climático e biológico da biosfera (STEFFEN et al., 2007; OPHULS, 2011; ELLIS, 2015; WILLIAMS et al., 2015). No contexto atual, a mitigação desses efeitos dependerá da reintegração do ser humano com a natureza, através de novos modelos de consumo e exploração de recursos naturais (OPHULS, 2011; BALVANERA et al., 2015).

Com o intuito de fomentar práticas sustentáveis e reverter parte dos danos causados pelo uso indiscriminado dos recursos foi desenvolvido o MILLENNIUM ECOSYSTEM ASSESSMENT - MEA, uma avaliação científica global sobre as condições dos ecossistemas e dos serviços ecossistêmicos. O MEA também propõe ações para a proteção, o uso sustentável dos ecossistemas e o bem-estar humano (MEA, 2005; ONU, 2015). Com base nesse relatório, a plataforma Intergovernamental Science-Policy Platform on Biodiversity and Ecosystem Services - IPBES (Plataforma Intergovernamental sobre Biodiversidade e Serviços Ecossistêmicos) realiza avaliações e orienta o desenvolvimento, implementação e evolução de projetos, visando auxiliar os governos e as instituições nas tomadas de decisões (JOLY et al., 2019; IPBES, 2020).

É chamado de "Serviço Ecossistêmico" a capacidade dos processos naturais em fornecer produtos e serviços para a humanidade, ou seja, os benefícios da natureza que são utilizados pelo ser humano para o seu próprio 
bem-estar (MEA, 2005; COSTANZA et al., 2017). Estes serviços podem ser divididos em de Provisão (produtos obtidos diretamente dos ecossistemas, e essenciais à vida como alimentos, fibras, recursos genéticos, produtos medicinais, água, madeira); de Suporte (de difícil percepção, mas que propiciam as condições necessárias para os demais serviços como produção de $0^{2}$, fertilidade do solo, diversidade biológica); de Regulação (regulam os processos como qualidade do ar, polinização, mitigação de danos naturais, doenças, controle de enchentes e erosão); e Cultural (valores religiosos e espirituais, geração de conhecimento, lazer) (MEA, 2005; JOLY et al., 2019).

Estes serviços são resultantes das complexas interações entre fatores bióticos e abióticos (DE GROOT et al., 2002), os quais podem ser impactados por ações antropogênicas que alteram processos ecológicos em dado ecossistema (KOSANIC; PETZOLD, 2020). Apesar da sociedade humana depender diretamente dos serviços ecossistêmicos, esta visão de interdependência ainda não é incorporada no mercado econômico (CAVALCANTI, 2012). Esse negligenciamento tem afetado a sustentabilidade da biosfera, diminuindo os estoques de produtos oriundos dos processos naturais (COSTANZA et al., 1997, CAVALCANTI, 2012).

É um grande desafio captar e analisar como as pessoas percebem a Biodiversidade e Serviços Ecossistêmicos (BSE) visto que indivíduos atribuem significados e valores muito particulares às funções ecossistêmicas, os quais variam de acordo com o conhecimento, a relação e a responsabilidade de cada indivíduo para com a natureza (DE GROOT et al., 2002; ARIAS-ARÉVALO et al., 2017; COSTANZA et al., 2017). As análises para se atribuir valor à natureza são divididas basicamente em três tipos: valor ecológico (mede os indicadores ecológicos como diversidade e integridade); valor sociocultural (mede a importância dada e o "apego" ou ligação das pessoas com um determinado ambiente); e valor econômico (de uso direto: como o uso de recursos; e de nãouso: como recreação, estética, purificação da água, prevenção de erosão, simples existência) (DE GROOT et al., 2010).

Diversos estudos mostram que os conceitos e os valores de ordem subjetiva das pessoas envolvidas na gestão e no planejamento de áreas naturais devem ser contemplados, enfatizando que a simples valoração monetária ou econômica é incompleta e insuficiente para expressar a totalidade das dimensões de "valor" que a sociedade atribui à natureza (DE GROOT et al., 2010; CHAN et al., 2012; COSTANZA et al., 2017; ARIAS-ARÉVALO et al., 2018). Sendo assim, valores associados ao uso indireto de serviços ecossistêmicos culturais, como contemplação de beleza cênica, possibilidade de realização de atividades de lazer/turismo, educativas, esportivas, estão relacionadas com a promoção do bem-estar e saúde humana (RUSSELL et al., 2013; COLLEY; CRAIG, 2019, KOSANIC e PETZOLD, 2020). Deste modo, é necessário avaliar a percepção das pessoas sobre estes serviços, uma vez que a maneira como a Natureza e a BSE são percebidos afeta diretamente as formas de utilização dos mesmos (DE GROOT et al., 2010; OLIVEIRA JUNIOR, COSTA; TAFURI, 2012; COSTANZA et al., 2017; ARIAS-ARÉVALO et al., 2018).

A percepção ambiental de modo geral, e a representação simbólica da natureza em particular, fazem parte de um processo complexo e multidimensional que passa pela cosmologia de uma dada sociedade, sendo também medida por 
disposições de comportamento e pela dimensão afetiva no nível individual (TUAN, 1980; TUAN, 1983; INGOLD, 2000). O aspecto topofílico (sentimento de afeto por um lugar), por exemplo, pode auxiliar na sensibilização e consequente mudança de comportamento das pessoas, com relação ao ambiente e aos serviços ecossistêmicos (TUAN, 1980; PEREIRA et al., 2018).

Áreas naturais próximas às cidades são vulneráveis a degradação ambiental, já que a urbanização causa considerável impacto sobre a integridade dessas florestas (PEIXOTO-GIACON, 2019) e sobre a manutenção da biodiversidade e dos serviços ecossistêmicos (ELMQVIST et al., 2015). Sabe-se que a preservação destas áreas contribui para a manutenção da qualidade do ar e da água, redução da poluição e da degradação do solo, manutenção do equilíbrio climático e conservação da biodiversidade (CARDOSO, 2010; MOMMSCHULT et al., 2014; ELMQVIST et al., 2015; NASCIMENTO et al., 2017).

Estas áreas também oferecem lazer, recreação, Educação Ambiental, turismo. Seja no âmbito dos serviços culturais, de regulação ou de provisão, proteger e restaurar esses ambientes se mostra atrativo inclusive do ponto de vista econômico (MOMM-SCHULT et al., 2014; ELMQVIST et al., 2015; MOTA et al., 2016).

Como parte do problema concreto a ser investigado neste artigo, dada a relevância para a conservação e a pressão por conta da expansão imobiliária na região de uma microbacia com interface urbano/rural do município de Boituva, surgiu a proposta da criação de um Parque Natural Municipal na microbacia do Ribeirão Pau D'Alho, em Boituva /SP (CARDOSO-LEITE et al., 2020). Um Parque Natural Municipal pode contribuir para aumentar a imagem turística do município, além de despertar a sociedade para a importância da preservação, já que as Unidades de Conservação - UCs na categoria "Parque" são normalmente associadas a qualidade de vida, uso público, ao turismo e recreação (VIEIRA e GÂNDARA, 2015; BRUMATTI et al., 2019). Isto porque "Parque (Nacional federal; Estadual - estadual; Natural Municipal - municipal)" é uma das categorias de Unidade de Conservação de Proteção Integral previstas no Sistema Nacional de Unidades de Conservação - SNUC (2000) que têm como objetivo a preservação de ecossistemas naturais de grande relevância ecológica e beleza cênica, permitindo a realização de pesquisas científicas, atividades de educação, recreação e de turismo ecológico.

O SNUC (2000) em seu Artigo 5 recomenda que se assegurem a participação efetiva das populações locais na criação, implantação e gestão das unidades de conservação, e em seu Artigo 22 recomenda a consulta pública antes da criação de uma Unidade de Conservação de Proteção Integral - UCPI. Sendo assim, o apoio das comunidades locais (entorno da área) para a criação de uma UC é muito significativo, tornando relevante acessar aspectos da percepção sobre BSE, da comunidade que vive próxima a essas áreas. Essas informações podem subsidiar a gestão e a tomada de decisões acerca dessa proposta incorporando os moradores locais como protagonistas desse processo, e evitando conflitos entre sociedade e tomadores de decisão (DE GROOT et al., 2010; BALVANERA et al., 2015; GIL; ROSA, 2017; COLLEY; CRAIG, 2019).

Neste contexto, o objetivo deste estudo foi analisar como os moradores percebem a "Biodiversidade e os Serviços Ecossistêmicos" na Bacia do Ribeirão Pau D'Alho, em Boituva/SP, e como avaliam a possível criação de um "Parque 
Natural Municipal" nesta microbacia, incorporando e aumentando a área do atual "Parque Ecológico Eugênio Walter".

\section{Materiais e Métodos}

\section{Caracterização da Área}

Boituva é um dos 140 municípios paulistas classificados como Município de Interesse Turístico (MITs) (BOITUVA 1, 2018) e reconhecido como a capital do paraquedismo no Brasil (BOITUVA 2, 2020). Encontra-se a $110 \mathrm{~km}$ da capital paulista, seguindo a rodovia Castello Branco sentido oeste, entre as coordenadas geográficas -23.2854 (latitude) e -47.674 (longitude). Possui 60.997 habitantes e uma área territorial de 248,95 $\mathrm{Km}^{2}$ (IBGE 1, 2020) e faz parte da Região Metropolitana de Sorocaba (RMS) e da Bacia Hidrográfica do Médio SorocabaTietê.

Visando o desenvolvimento sustentável, foi realizado no município um projeto com a finalidade de subsidiar o planejamento ambiental e propor a criação de áreas de proteção, que resultou no mapeamento da vegetação, dos recursos hídricos e na indicação de áreas a serem protegidas (CARDOSO-LEITE et al., 2020). Uma das áreas apresentadas como de alta prioridade de conservação, a Bacia do Ribeirão Pau D'Alho, localiza-se entre as rodovias SP-280 Presidente Castello Branco e SP-129 Vicente Palma (Boituva - Porto feliz). É próxima ao centro urbano e empresarial da cidade, dispondo de forte presença de condomínios e de áreas agrícolas, apresentando grande fragilidade ambiental, devido à intensa especulação imobiliária (CARDOSO-LEITE et al., 2020).

A Bacia do Ribeirão Pau D'Alho corre em direção NE desaguando no Rio Tietê, e por ser uma região com alta densidade de drenagem, contribui para a presença de mananciais e fragmentos de remanescentes de Mata Atlântica na região. Os fragmentos 54 e 55 (Figura 1) são áreas do já existente "Parque Ecológico Eugênio Walter".

Uma sugestão indicada pelo estudo realizado por Cardoso-Leite et al., (2020) é a criação de uma Unidade de Conservação de Proteção Integral (UCPI), desapropriando áreas privadas e recategorizando toda a extensão em Parque Natural Municipal. Essa UCPI formaria uma bacia modelo, através da conexão e restauração dos vestígios de mata existentes nos fragmentos $50,51,53,54,55$, 141, 142 e 143, em destaque na Figura 1, detalhando os fragmentos considerados na proposta citada.

A área do "Parque Ecológico Eugênio Walter" (fragmentos 54 e 55, Figura1) possui em seu entorno condomínios. Com aproximadamente 136 mil metros quadrados, é uma área de preservação de mananciais naturais e vegetação típica da Mata Atlântica. Conta com um viveiro de mudas nativas as quais são utilizadas no reflorestamento de microbacias da região (BOITUVA 3, 2020). Além da preservação, os objetivos do parque são reduzir os impactos negativos de resíduos na comunidade e integrar a população e Educação Ambiental (BOITUVA 4, 2019). 


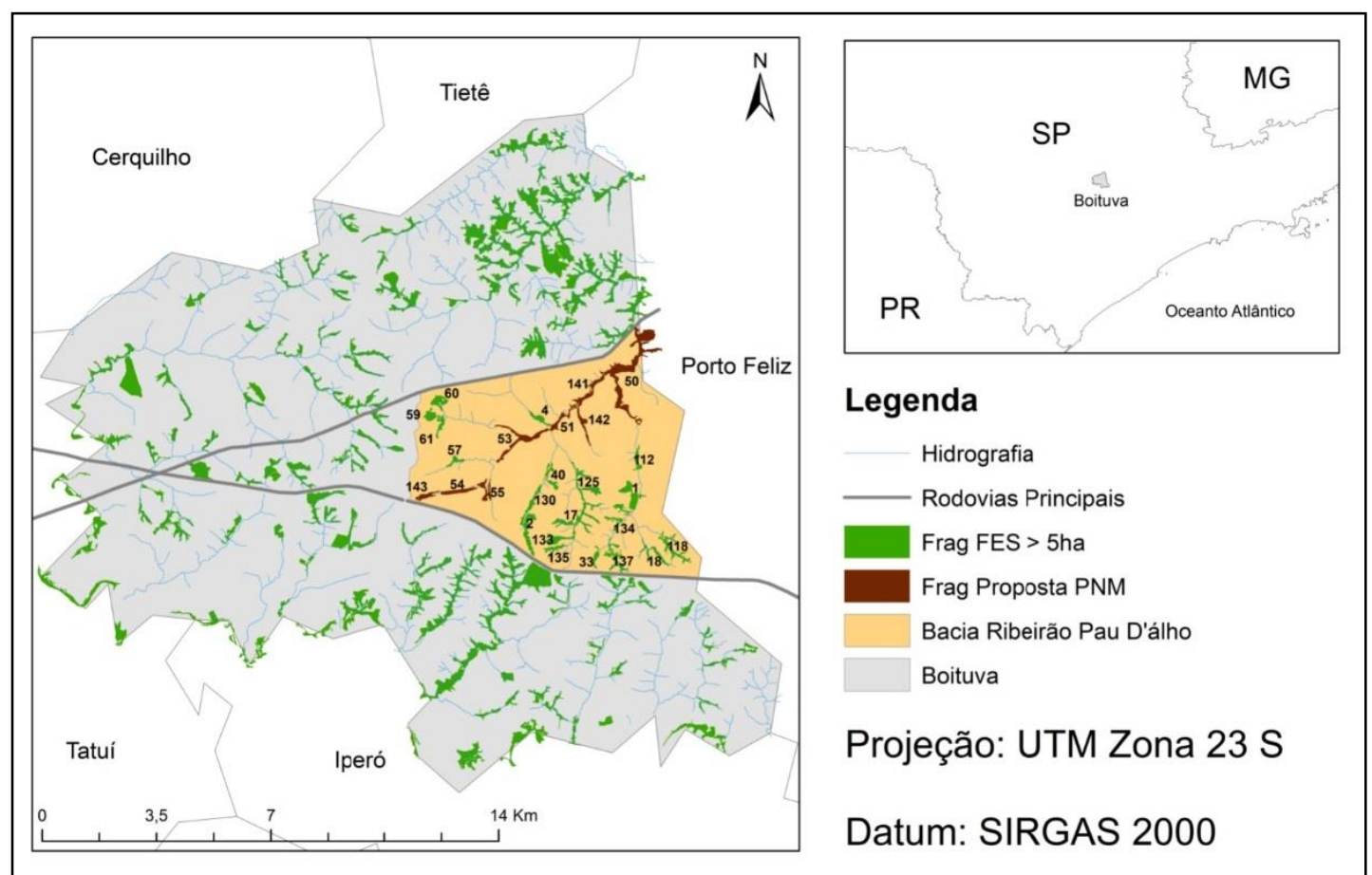

Figura 1: Mapa da microbacia do Ribeirão Pau D'Alho e fragmentos remanescentes de Mata

Atlântica em Boituva, destacando aqueles que formam o proposto PNM, SP, Brasil.

Figure 1: Map of Ribeirão Pau D'Alho's microbasin and Atlantic Rain Forest remnants in Boituva, highlighting those that form the proposed Natural Municipal Park, SP, Brazil.

Fonte: Cardoso-Leite; Arruda; Valente (2020). Editado pelos autores (2021).

Source: Cardoso-Leite; Arruda; Valente (2020). Edited by the authors (2021).

Atividades de turismo e de extensão e pesquisa sobre meio ambiente pelo Instituto Federal de Educação, Ciência e Tecnologia de São Paulo (IFSP) são realizadas no parque (CARDOSO-LEITE et al., 2020), que foi enquadrado como zoológico pelo IBAMA em 2013. Este funciona como um centro de reprodução de aves migratórias e possui algumas espécies de aves, mamíferos e répteis em cativeiro, em sua maioria, animais que foram apreendidos do tráfico ou atropelados, como demonstrado na Figura 2.

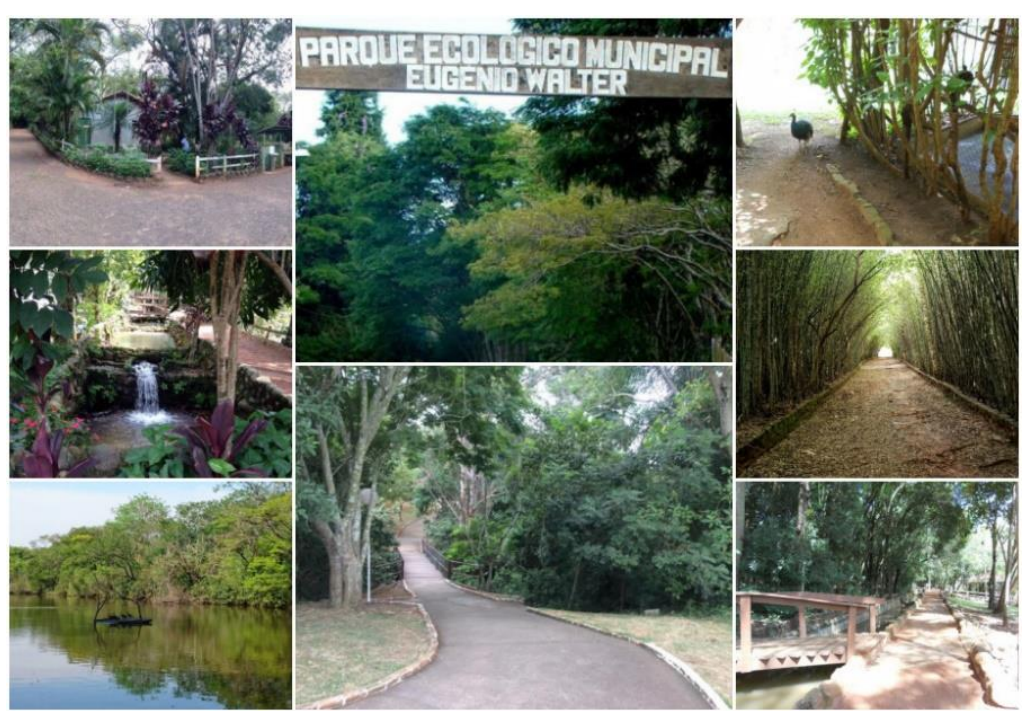

Figura 2: Fotos do Parque Ecológico Eugênio Walter em Boituva, SP, Brasil.

Figure 2: "Parque Ecológico Eugênio Walter" park's photographs in Boituva, SP, Brazil.

Fonte: Prefeitura Municipal de Boituva, organizado pelos autores.

Source: Boituva Municipality, organized by authors. 
O fragmento 50 possui boa integridade biótica (CARDOSO-LEITE; ARRUDA; VALENTE, 2020), e embora pertença a uma propriedade privada, possui algumas trilhas possivelmente já utilizadas para lazer. Neste fragmento existe a chamada "Roda D’água" (Figura 3) que é um local procurado por turistas.
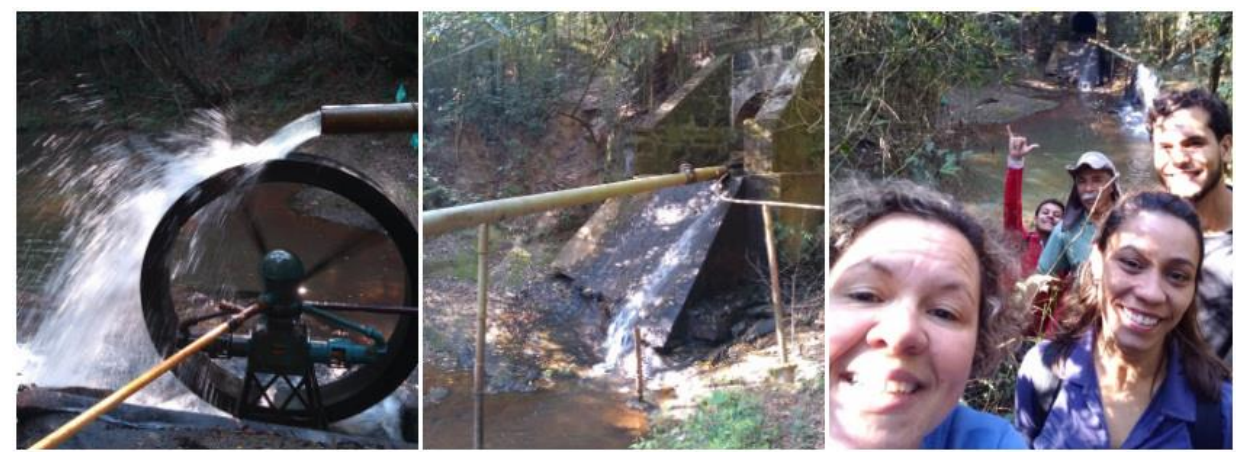

Figura 3: Fotos da "Roda D’água" existente no Fragmento 50, em Boituva, SP, Brasil.

Figure 3: "Roda D'água" (Waterwheel) photographs present in the fragment 50 , in Boituva, SP, Brazil. Fonte: Eliana Cardoso-Leite, organizados pelos autores.

Source: Eliana Cardoso Leite, organized by authors.

\section{Coleta de Dados}

Este estudo de caráter exploratório (GIL, 2009), se baseou na aplicação de entrevistas em formato semiestruturado, aplicados aos moradores da bacia do Ribeirão Pau D'Alho com mais de 18 anos de idade. Os registros foram realizados entre setembro de 2020 e março de 2021.

Tanto moradores de áreas rurais quanto das áreas urbanas, estes últimos, principalmente do entorno do "Parque Ecológico Eugênio Walter" foram abordados, sendo a amostra determinada de forma aleatória e oportunista, considerando a disponibilidade e consentimento dos participantes (GIL, 2009).

Durante a entrevista, foram abordadas questões abertas e fechadas acerca da visão sobre serviços ecossistêmicos, com enfoque no conhecimento da existência de áreas verdes próximas à residência de cada entrevistado. As questões aplicadas visaram registrar o significado, o valor, ou a importância atribuída pelo entrevistado às áreas verdes de seu entorno.

Cada resposta narrada foi transcrita em questionário individual, com o consentimento livre e esclarecido dos participantes e previa explicação do motivo da pesquisa (GIL, 2009). Dessas respostas, buscou-se extrair a ideia central, ou uma expressão chave, que foi utilizada para classificar quais os serviços ecossistêmicos mais notados (SOUSA; SANTOS, 2010; DICTORO et al., 2016). Também foi avaliada a opinião dos entrevistados sobre a possível criação de um Parque Natural Municipal na microbacia.

Por fim, foram captadas informações para caracterizar 0 perfil socioeconômico dos entrevistados, analisando gênero, idade, grau de escolaridade, renda média familiar, a quanto tempo mora ou na área rural, ou urbana, e onde morou na infância. 


\section{Questões utilizadas na Entrevista}

1. Você reconhece alguma mata (floresta, área verde) próxima à sua casa/propriedade? Qual?

2. Você considera "Muito positivo", "Mais ou menos positivo" ou "Pouco positivo" ter esta mata próxima à sua casa/propriedade? Opções de resposta: Muito positivo (10); mais ou menos (5); ou pouco positivo (1).

2.1. Você poderia descrever quais são os pontos positivos, ou benefícios, que essa mata traz para você, seu bairro ou sua propriedade?

3. Se aquela mata sobre a qual falamos no início fosse transformada em uma área de proteção (onde as pessoas não podem pescar, caçar, retirar madeira ou outros produtos, mas visitar como turistas) você: "apoiaria completamente" (10), "apoiaria apenas em parte" (5) ou "não apoiaria" (1)?

\subsection{Por quê?}

Caracterização de perfil socioeconômico

4. Onde viveu na Infância? Zona urbana ou rural?

5. Sua idade, questão por faixas: de 18 a 29; 30 a 39; 40 a 49; 50 a 59; 60 a 69; e 70 ou mais.

6. Seu grau de escolaridade, também questionado por faixas: Ensino Fundamental; Ensino Médio; e Ensino Superior.

7. Renda média da família - soma salários de todas as pessoas da família. Categorizadas como: Até 3 salários mínimos (1); de 3,1 a 6 salários mínimos (2); de 6,1 a 9 salários mínimos (3); de 9,1 a 12 salários mínimos (4); de 12,1 a 15 salários mínimos (5); e Acima de 15 salários mínimos (6).

\section{Análise dos Dados}

Os dados foram analisados de forma quantitativa (questões 1, 2, 3) para mensurar as informações e qualitativa (questões 2.1, 3.1) para compreender a condição mais subjetiva do entendimento sobre BSE (FREITAS; JABBOUR, 2011).

Para as questões abertas, foi utilizada a abordagem analítica baseada na identificação de palavras-chave ou metáforas, propostas por ARIAS-ARÉVALO et al. (2018), que definiu uma tabela de valores a serem considerados e classificou essa compreensão através de metáforas acerca da relação homem-natureza.

Cada resposta utilizada para descrever os benefícios de se ter uma mata ou área verde próxima e a motivação por concordarem com a criação de uma UCPI, além de algumas citações feitas durante o decorrer do diálogo, foram anotadas. Dessas respostas, as metáforas sinônimas foram agrupadas e interpretadas, criando uma tabela de metáforas citadas, as quais foram comparadas à tabela de classificação sobre a relação homem-natureza de ARIAS-ARÉVALO et al. (2018), determinando, assim, a qual serviço ecossistêmico cada grupo de metáforas se relacionava.

Por meio da análise de frequência das respostas foi possível evidenciar quais foram os serviços ecossistêmicos mais percebidos pelos entrevistados da área urbana e da área rural, em uma perspectiva comparativa. 


\section{Resultados e Discussão}

\section{Perfil dos entrevistados}

Participaram da pesquisa 37 pessoas, sendo 51\% dos entrevistados moradores da área urbana localizada no entorno do "Parque Ecológico Eugênio Walter" e 49\% moradores da área rural. Existem quatro grandes propriedades na região do Ribeirão Pau D'Alho e nenhum dos proprietários se propôs a participar da pesquisa, apesar das diversas tentativas junto aos mesmos. Trata-se de um "Haras" (criação de cavalos), uma área de piscicultura e duas áreas de produção de soja e gado.

A maioria dos entrevistados (68\%) tinha entre 30 e 59 anos de idade, $19 \%$ tinham mais de 60 anos e 13\% com idades entre 18 e 29 anos.

Considerando o grau de escolaridade verificou-se que grande parte dos entrevistados tinha ensino médio (32\%) ou apenas o ensino fundamental (30\%). Questionados sobre a renda média familiar, $65 \%$ dos entrevistados afirmaram ter renda média de até 3 salários-mínimos, $26 \%$ de 3,1 a 6 salários-mínimos, $6 \%$ de 6,1 a 9 , e apenas $3 \%$ entre 12,1 a 15 salários. Segundo a Pesquisa Nacional por Amostra de Domicílios Contínua o rendimento médio mensal do brasileiro é menor que 3 salários-mínimos (IBGE 2, 2020).

Quarenta e oito porcento dos entrevistados afirmaram ter vivido a infância em cidade classificada como rural ou de pequeno porte (menos de 50 mil habitantes), $23 \%$ em cidade de médio porte (de 50 a 100 mil habitantes) e $29 \%$ em uma capital ou cidade de grande porte (mais de 100 mil habitantes), seguindo os critérios de classificação do espaço urbano e rural de COSTA; NARDELLI (2009). Segundo alguns autores (ARIAS-ARÉVALO et al., 2017; COLLEY; CRAIG, 2019), as experiências sociais e culturais, principalmente aquelas vividas na infância, podem influenciar ou definir a maneira como a natureza é percebida por indivíduos adultos.

Em síntese, a maioria dos entrevistados apresentou idade entre 30 e 59 anos, renda de até 3 salários-mínimos e ensino fundamental ou médio, tendo vivido a infância em cidade de pequeno porte ou médio porte.

\section{Percepção dos entrevistados sobre BSE e criação de uma UC}

Estudos semelhantes foram realizados em diferentes cenários e com diversas abordagens com o objetivo de analisar a percepção das pessoas sobre os serviços ecossistêmicos. Por exemplo, a percepção dos usuários de fazendas particulares, que tem como foco o ecoturismo, localizadas em regiões de APA em Goiás foi registrada por Sousa e Santos (2010), e por Lira e Pelicice (2020) no Tocantins. A percepção dos visitantes de Parques, foi investigada por Oliveira Junior, Costa e Tafuri (2012) no Parque estadual do Itacolomi - MG. Verifica-se também estudos sobre a percepção de fazendeiros, como o realizado por Blanco et al. (2020) nas florestas rurais do sudoeste da França, e por Ahammad, Stacey e Sunderland (2019), com agricultores na região de Chittagong Hill Tracts em Bangladesh.

Questionados sobre o reconhecimento de alguma mata próxima à residência (Questão 1), 89,5\% dos moradores da área urbana e 88,9\% da área rural afirmaram que reconheciam as áreas verdes próximas a eles, enquanto 
$10,5 \%$ do urbano e $12,5 \%$ do rural disseram não reconhecer, evidenciando que não houve diferença de percepção entre moradores rurais e urbanos a este respeito. Estes resultados concordam com diversos estudos que apresentam mais de $80 \%$ de respostas afirmativas para o reconhecimento e identificação de áreas verdes no entorno de onde essas pessoas residem (OLIVEIRA JUNIOR et al., 2012; PEREIRA et al., 2018; UJHÁZY et al., 2020).

Quando questionados se consideravam positiva ou negativa a presença de uma mata próxima à sua residência (Questão 2), a resposta foi unânime (100\%) para positiva. Porém, quando abordados sobre o quanto positivo isso seria, $94,7 \%$ dos moradores urbanos e $94,7 \%$ dos rurais afirmaram ser "muito positivo", enquanto $5,3 \%$ de moradores urbanos indicaram "mais ou menos positivo" e 5,3\% dos rurais como "pouco positivo" (Figura 4).

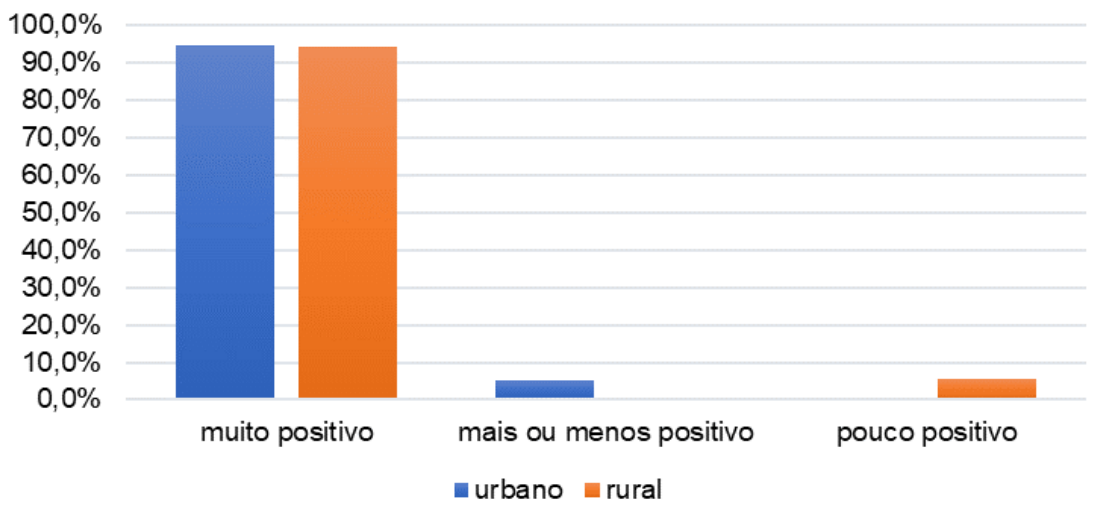

Figura 4: Percepção sobre a existência de "mata" próxima às residências dos entrevistados, na microbacia do Ribeirão Pau D'Alho, Boituva/SP, Brasil.

Figure 4: Perception of the existence of "forests" near the interviewees' residences, in Ribeirão Pau D'Alho's micro-basin, Boituva, SP, Brazil.

Fonte: Elaborado pelos autores (2021).

Source: Elaborated by the authors (2021).

É comum as pessoas apresentarem sentimentos positivos em relação aos parques e áreas verdes (MOMM-SCHULT et al., 2014; PEREIRA et al., 2018) fazendo com que os benefícios percebidos estimulem que a própria população local se empenhe em cuidar e manter essas áreas (GIL; ROSA, 2017; FRANÇA et al., 2018; SANTOS et al., 2019; LIRA; PELICICE, 2020). Os aspectos considerados para que a resposta não fosse totalmente positiva referem-se ao fato de que áreas naturais, quando abandonadas ou mal geridas, acabam tornando-se locais propensos a violência e atos ilícitos (MELO et al., 2016; GIL; ROSA, 2017; LIRA; PELICICE, 2020).

A maneira utilizada para avaliar a percepção sobre os serviços ecossistêmicos foi relacionando as metáforas utilizadas para responder duas questões (questões 2.1 e 3.1). As respostas foram registradas, organizadas na Tabela 1 e correlacionadas aos serviços ecossistêmicos seguindo critérios propostos por Arias-Arévalo et al. (2018), mas com interpretação das "metáforas" feitas pelos autores. Vale ressaltar que uma mesma afirmação (ou metáfora) poderia ser relacionada a um ou mais serviços.

Tabela 1: Metáforas relacionadas aos BSE como respostas às questões 2.1 e 3.1, de entrevistados residentes na microbacia do Ribeirão Pau D’Alho, Boituva/SP, Brasil 
Table 1: Table 1: Biodiversity and ES related metaphors as answers to questions 2.1 and 3.1, from the interviewees in Ribeirão Pau D'Alho's micro-basin, Boituva, SP, Brazil.

\begin{tabular}{|c|c|c|c|c|c|c|c|c|}
\hline \multirow{2}{*}{ Metáforas } & \multicolumn{4}{|c|}{ Rural } & \multicolumn{4}{|c|}{ Urbano } \\
\hline & provisão & suporte & regulação & cultural & provisão & suporte & regulação & cultural \\
\hline $\begin{array}{l}\text { o ar é diferente/ é melhor/ mais } \\
\text { fresco }\end{array}$ & & & 13 & & & & 8 & \\
\hline $\begin{array}{l}\text { mais gostoso/ prazeroso/ } \\
\text { bacana }\end{array}$ & & & & 11 & & & & 5 \\
\hline $\begin{array}{l}\text { mais bonito, a natureza é muito } \\
\text { bonita }\end{array}$ & & & & 3 & & & & 3 \\
\hline o que é do mato fica no mato & 1 & & & & & & & \\
\hline mais acesso à alimento & 1 & & & & & & & \\
\hline mais liberdade & & & & 1 & & & & 2 \\
\hline ouvir/ver os animais & & & & 1 & & & & 3 \\
\hline $\begin{array}{l}\text { ter mais água/ protege a água/ } \\
\text { água boa }\end{array}$ & 1 & & 2 & & & & & \\
\hline viver da área rural & 1 & & & & & & & \\
\hline tranquilidade/ paz/calma & & & & 5 & & & & 4 \\
\hline $\begin{array}{l}\text { preservar/ quanto mais natureza } \\
\text { melhor }\end{array}$ & 2 & & & 2 & 2 & & & 2 \\
\hline importante apenas ter/ essência & & 3 & & & & 2 & & \\
\hline $\begin{array}{l}\text { melhora a saúde/ reduz } \\
\text { doenças }\end{array}$ & & & 2 & & & & 2 & \\
\hline lazer/ turismo & & & & 1 & & & & 4 \\
\hline cheiro bom & & & & & & & & 1 \\
\hline $\begin{array}{l}\text { se não cuidar a natureza se } \\
\text { vinga, o bicho homem acaba } \\
\text { com tudo }\end{array}$ & & & & & 1 & & 1 & 1 \\
\hline faz bem para o ser humano & & 1 & & & & 1 & & 1 \\
\hline microclima fica diferente & & & & & & 1 & 1 & \\
\hline ficar feliz/vida vale a pena & & & & 1 & & & & 1 \\
\hline o verde faz chover mais & & & & & & 1 & & \\
\hline $\begin{array}{l}\text { preocupação com as futuras } \\
\text { gerações }\end{array}$ & & & & & & 2 & & \\
\hline ecossistema para os animais & & & & & & 1 & & \\
\hline Abrigo & & & & & 1 & & & \\
\hline árvore produz oxigênio & & & & & & & 1 & \\
\hline tem q ter arvore, sombra & & & & & & & 1 & \\
\hline $\begin{array}{l}\text { o que a natureza produz é muito } \\
\text { valioso }\end{array}$ & & & & & & 1 & & \\
\hline faz bem estar perto da natureza & & & & 1 & & & & 1 \\
\hline lugar sem natureza não é bom & & & & & & 1 & & \\
\hline $\begin{array}{l}\text { tem q preservar porque está } \\
\text { diminuindo }\end{array}$ & 2 & & & & & & & \\
\hline $\begin{array}{l}\text { precisa também construir casa } \\
\text { e produzir alimento }\end{array}$ & 1 & & & & & & & \\
\hline $\begin{array}{l}\text { abraçar um arvore para trocar } \\
\text { energia }\end{array}$ & & & & 1 & & & & \\
\hline faz mais sentido & & & & 1 & & & & \\
\hline menos poluição & & & 1 & & & & & \\
\hline Total & 9 & 4 & 18 & 28 & 4 & 10 & 14 & 28 \\
\hline
\end{tabular}

Fonte: Elaborado pelos autores (2021).

Source: Elaborated by the authors (2021). 
Os dados da Tabela 1 foram utilizados para elaboração da Figura 5, que mostra os serviços ecossistêmicos mais percebidos pelos moradores das áreas urbana e rural. O confronto entre as percepções dos entrevistados do meio urbano e do meio rural sugere um padrão semelhante de percepção dos serviços ambientais por estes dois grupos (Figura 5).

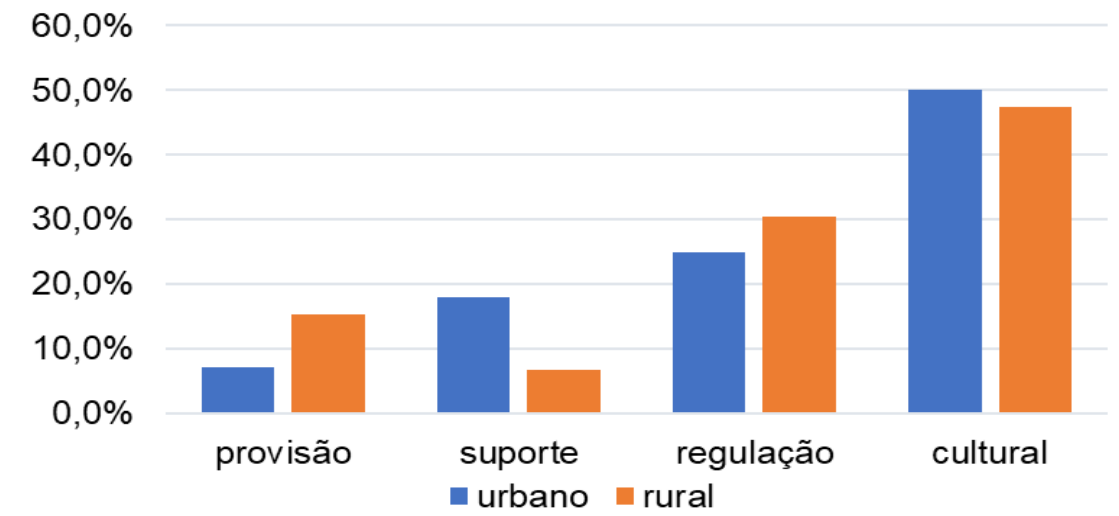

Figura 5: BSE mais percebidos quando metáforas foram usadas, na microbacia do Ribeirão Pau D’Alho, Boituva/SP, Brasil.

Figure 5: Most perceived Biodiversity and ES while metaphors were used, in Ribeirão Pau D'Alho's micro-basin, Boituva, SP, Brazil.

Fonte: Elaborado pelos autores (2021).

Source: Elaborated by the authors (2021).

Os serviços culturais foram os mais citados $(50 \%$ dos entrevistados da área urbana e $47,5 \%$ da área rural). Informações semelhantes às obtidas nesta pesquisa foram relatadas em estudos realizados por Gil e Rosa (2017), Mamede et al. (2018), Panassolo et al. (2019), Lira e Pelicice (2020) e Ostóic et al. (2020). Nestes estudos foi enfatizado que essa empatia por estar em contato com a natureza tem propensão à ligação emocional que os seres humanos têm com a natureza.

Vale salientar que neste estudo os representantes rurais perceberam mais os serviços culturais, $50 \%$ dos moradores de áreas urbanas e $47,5 \%$ dos moradores de áreas rurais citaram metáforas relacionadas a sensação de prazer e bem-estar. Este padrão diverge dos resultados encontrados por Ahammad et al., (2019), com agricultores na região de Chittagong Hill Tracts em Bangladesh e dos resultados obtidos pelo estudo de Blanco et al. (2020), com produtores rurais do sudoeste francês. Ambos os estudos resultaram que moradores dessas regiões rurais reconheceram, sobretudo, os serviços de provisão (alimentos, energia) e de regulação.

Para os moradores da Microbacia do Ribeirão Pau D'Alho o segundo serviço mais percebido foi 0 de regulação, sendo citados por $25 \%$ dos entrevistados da área urbana e 30,5\% dos entrevistados da área rural. A principal metáfora citada relacionada aos serviços de regulação foram "questões associadas ao clima e qualidade do ar" (Tabela 1), concordando com resultados obtidos por Mamede et al. (2018); Panassolo et al. (2019) e Lira e Pelicice (2020). Esta percepção deve estar associada por um lado à expansão urbana que aumenta a poluição do ar, assim como algumas técnicas de manejo utilizadas em áreas agrícolas como "as queimadas". 
O serviço de provisão foi o terceiro serviço (Figura 5) mais percebido pelos moradores da área rural, sendo citados por $15,3 \%$. Isto deve estar relacionado ao fato de moradores de áreas rurais dependerem dos produtos obtidos diretamente dos ecossistemas, como também enfatizado pelo estudo de Blanco et al. (2020), entre moradores rurais do sudoeste da França.

Já entre os moradores urbanos entrevistados, apenas $7,1 \%$ reconheceram os serviços de provisão. Isto pode estar associado ao fato de que moradores de áreas urbanas geralmente se beneficiam de processos e produtos oriundos de serviços ambientais através de complexas cadeias de produção, transporte e comércio distantes de seu local de consumo. Nessa situação, os serviços ecossistêmicos se tornam difusos e menos perceptíveis aos indivíduos, proporcionando a falsa sensação de independência em relação aos processos naturais (MAMEDE et al., 2018; COLLEY; CRAIG, 2019; LIRA; PELICICE, 2020).

Os serviços de suporte (Figura 5 ) foram os menos notados pelos moradores da área rural da microbacia, apenas 6,8\% citaram metáforas relacionadas a esse serviço. Para os agricultores entrevistados por Ahammad et al. (2019) e Blanco et al. (2020) também pareceu difícil perceber os serviços de suporte, a menos que estes fossem sugeridos pelos entrevistadores. Já 17,9\% dos moradores das áreas urbanas (Figura 5) citaram metáforas relacionadas a esses serviços. Os resultados relativos ao suporte parecem contrariar àqueles acerca da regulação quanto às comparações entre rural e urbano, o que poderá ser melhor compreendido por estudos futuros na região. A percepção altruísta, relacionado a biodiversidade, simples existência e manutenção desses serviços também foi obtida em estudos de Arias-Arévalo et al. (2018); Mamede et al. (2018); Colley e Craig (2019); Lira e Pelicice (2020), que frisaram a preocupação com as futuras gerações.

Quando questionados sobre o apoio total, parcial ou o não-apoio para transformação da área de mata e criação de um Parque Natural Municipal (questão 3), seguindo as regras e definições do SNUC (2000), a maioria dos entrevistados declarou apoiar completamente a criação de uma Unidade de Conservação (Figura 6).

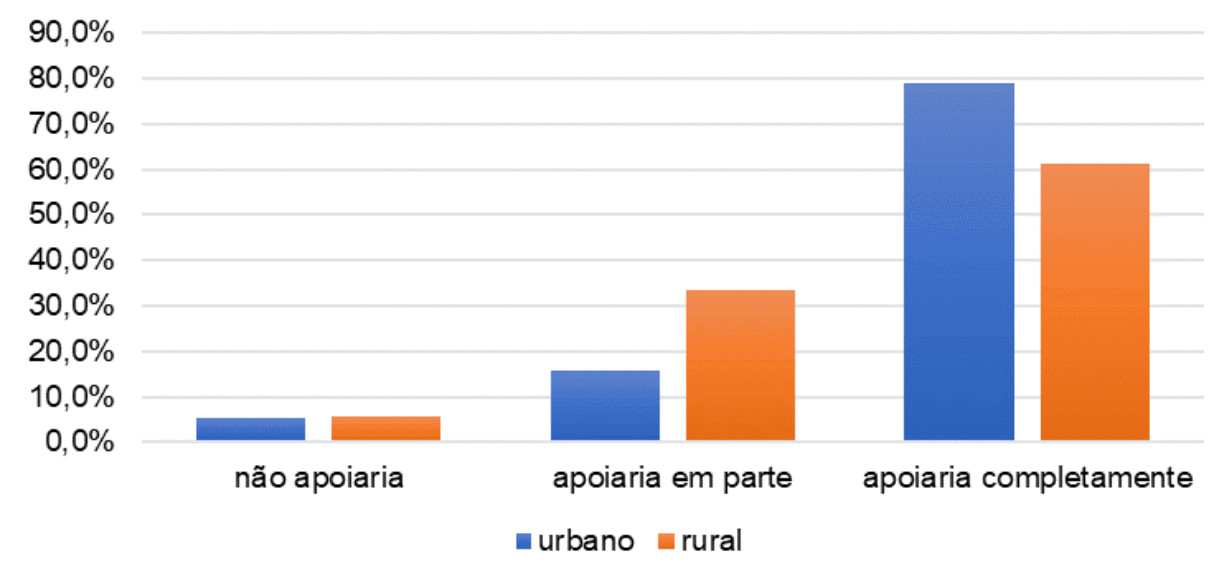

Figura 6: Apoio à conversão da área verde próxima à residência em um Parque NATURAL Municipal, na microbacia do Ribeirão Pau D’Alho, Boituva/SP, Brasil

Figure 6: Near residence green area conversion to "Parque Natural Municipal" (Municipal Natural Park) support, in Ribeirão Pau D’Alho's micro-basin, Boituva, SP, Brazil

Fonte: Elaborado pelos autores (2021).

Source: Elaborated by the authors (2021). 
A maioria dos entrevistados de origem urbana (78,9\%) afirmou concordar completamente com a criação de um Parque Natural Municipal e 15,8\% afirmou concordar parcialmente. Dentre os entrevistados de origem rural, $61,1 \%$ concordaram completamente, e $33,3 \%$ afirmou concordar parcialmente com a criação de UCPI. Esta menor proporção de apoio a criação de uma UC por parte dos proprietários rurais pode estar relacionada ao fato de não saberem exatamente o local onde seria esta nova UC (o local exato não foi esclarecido na entrevista) e talvez por interpretarem a criação de uma UC como uma restrição de uso de "matas" dentro de suas propriedades, ou mesmo devido ao temor de uma possível desapropriação de terras pelo poder público. Recordando que as restrições de uso na área da UC a ser criada foram citadas na própria questão 3. Os entrevistados que não apoiaram a criação de uma UCPI foram 5,3\% da área urbana e 5,6\% da área rural. Vale também registrar que quatro grandes proprietários (aproximadamente $22 \%$ das propriedades rurais existentes na microbacia) não aceitaram ser entrevistados. Desta forma, todos os entrevistados de origem rural eram pequenos ou médio proprietários.

As motivações citadas pelos entrevistados para o apoio à criação (Questão 3.1) de uma UCPI estavam relacionadas à "importância de cuidar do planeta", "garantir um futuro saudável", "manter a biodiversidade" e "garantir o contato com a natureza" (Tabela 1). Entretanto, a criação de uma UCPI pode gerar conflitos quando a opinião da comunidade envolvida não é considerada, uma vez que para o enquadramento nas categorias de UCPI muitas vezes requer desapropriações, adequações de zoneamento e um planejamento apropriado. Desta forma, os resultados deste estudo poderão auxiliar o poder público na implementação e criação de novas áreas protegidas, na microbacia do Ribeirão Pau D'Alho.

Segundo Costanza et al. (2017), maioria das pesquisas realizadas com serviços ecossistêmicos não tinha como foco os serviços culturais. Isto foi constatado nesta pesquisa, que explorou o que havia sido realizado desde que a valoração dos serviços ecossistêmicos foi questionada, ou seja, a 20 anos atrás, apontando para a fraqueza das abordagens, em particular as econômicas, e fornecendo recomendações para o futuro. Os estudos de Chan et al. (2012) já citavam as dificuldades de se extrair a percepção sobre valores associados aos serviços ecossistêmicos culturais, ressaltando que estes ainda não eram incorporados nas tomadas de decisão.

Atualmente, estudos sobre a percepção dos serviços culturais ressaltam sua relação com a promoção de valores educacionais e inspiracionais, além de provocar transformações comportamentais no âmbito ecológico (MAMEDE et al., 2018; PANASSOLO et al., 2019). Segundo Russel et al. (2013) as pessoas vivenciam os ecossistemas de maneira multissensorial, tornando-se mais felizes e saudáveis, o que fortalece os argumentos para que o poder público delimite e proteja áreas naturais, como por meio da criação de unidades de conservação.

A cidade de Boituva é reconhecida como um MIT (Município de Interesse Turístico) e isto pode ter influenciado no resultado deste estudo uma vez que as atividades turísticas realizadas em Boituva (Figura 7) estão associadas a ambientes naturais. Tanto para o balonismo quanto para o paraquedismo é importante manter áreas naturais, já que a grande beleza cênica é muito valorizada na prática dessas atividades. Nesse sentido, os serviços culturais, como contemplação de beleza, recreação e lazer, podem estar mais salientes no 
modo como os moradores de Boituva percebem os serviços ambientais de um modo geral. A associação da natureza com qualidade de vida aproxima a sociedade, fortalecendo o interesse dos próprios moradores em preservar, além de agregar valores, atraindo mais investimentos para a região (VIEIRA; GÂNDARA, 2015; BRUMATTI et al., 2019).

O título de Capital Nacional do Paraquedismo atrai turistas em busca de adrenalina e contato com a natureza, e consequentemente, estimula a presença de empreendimentos como sítios-pousadas, chácaras de veraneio, cursos e passeios de balão e paraquedismo, evidenciando a necessidade de políticas de preservação ambiental.

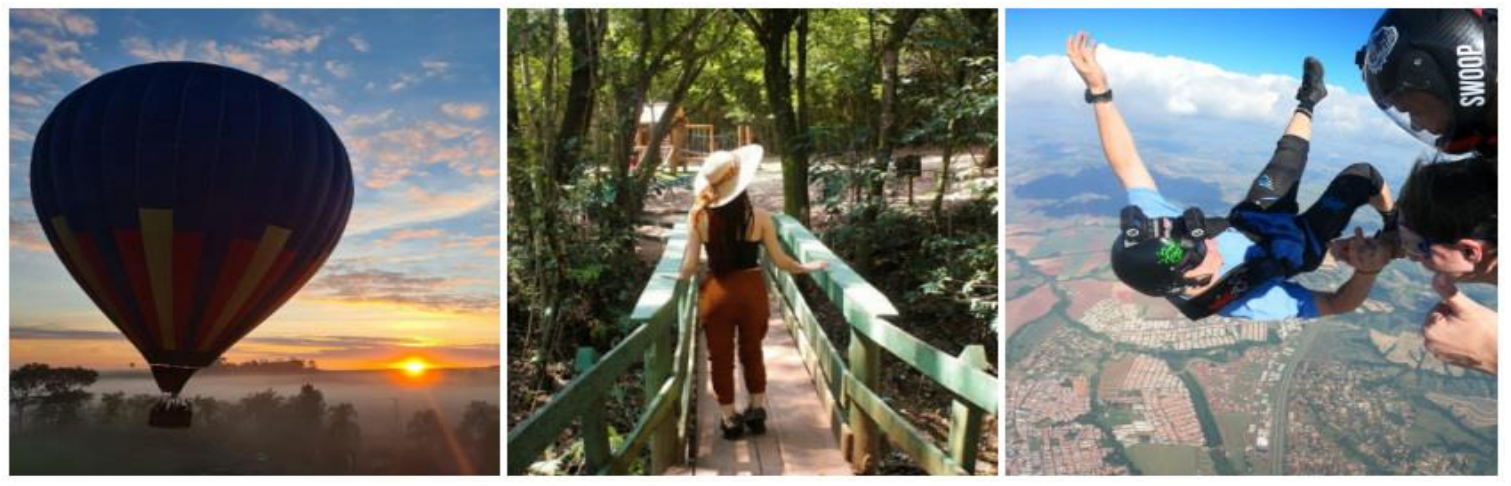

Figura 7: Fotos dos atributos turísticos: balonismo, "Parque Ecológico Eugênio Walter" e paraquedismo, em Boituva, SP, Brasil.

Figure 7: Photos of touristics attributes: ballooning, "Eugênio Walter Ecological Park" and parachuting, in Boituva, SP, Brazil.

Fonte: Prefeitura Municipal de Boituva, organizado pelos autores.

Source: Boituva Municipality, organized by authors.

Ao delimitar e criar uma área protegida é importante que se considere o ponto de vista da população envolvida, para além da realização de estudos técnicos e monitoramentos já consagrados pela legislação Brasileira (SNUC, 2000; BRASIL-MMA, 2019). No caso de Boituva/SP a criação de um PNM foi recomendada por estudo técnico prévio (CARDOSO-LEITE, ARRUDA e VALENTE, 2020) e os resultados da presente análise mostram que a população entrevistada concorda com esta proposta, e anseia pela criação de mais espaços naturais para lazer e turismo.

A vivência em meio a uma pandemia, como atual de Covid-19, tende a amplificar a demanda das pessoas por alguma forma de contato com a Natureza, visando seu bem-estar físico e emocional (RUSSELL et al., 2013; BATISTA, 2021).

\section{Considerações Finais}

Analisando a percepção dos diferentes moradores da bacia do Ribeirão Pau D'Alho, percebeu-se que tanto moradores da área mais rural quanto da área urbanizada possuem visões semelhantes percebendo a existência dos serviços ecossistêmicos. No entanto, vale ressaltar que um número considerável de proprietários rurais (22\% do total) não concordou em participar da entrevista, mesmo após várias tentativas. Isso demonstra que existe alguma resistência por parte de proprietários rurais, especialmente os grandes proprietários, em discutir qualquer tema relacionado à questão ambiental. 
Os Serviços Ecossistêmicos que mais foram reconhecidos pelos entrevistados foram a sensação de bem-estar, tranquilidade/paz/calma, qualidade do ar, que são respectivamente, serviços culturais e de regulação. Não obstante, também foram reconhecidas as caraterísticas importantes dos outros serviços.

Os resultados deste estudo evidenciaram também que a população da microbacia estudada concorda com a possível criação de uma UCPI ou um Parque Natural Municipal.

O fato de os entrevistados residirem em um "município de interesse turístico" parece ter influenciado a percepção dos envolvidos. Possivelmente, o momento da realização deste estudo, configurado por isolamento social devido à existência de uma pandemia, aumentou a percepção dos entrevistados sobre a necessidade de contato com a natureza, visto que essa relação traz efeitos positivos na saúde física e mental das pessoas.

Os resultados evidenciaram que a população entrevistada percebe os serviços ecossistêmicos, especialmente os serviços culturais e de regulação, e anseia por mais áreas naturais de lazer, recreação e turismo, em Boituva/SP, desta forma, os resultados aqui apresentados poderão subsidiar políticas públicas para criação de novas áreas de proteção ambiental neste município.

\section{Referências}

AHAMMAD, R.; STACEY, N.; SUNDERLAND, T. C. H. Use and perceived importance of forest ecosystem services in rural livelihoods of Chittagong Hill Tracts, Bangladesh. Ecosystem Services, v. 35, p. 87-98, 2019.

ARIAS-ARÉVALO, P.; GÓMEZ-BAGGETHUN, E.; MARTÍN-LÓPEZ, B.; PÉREZRINCÓN, M. Widening the Evaluative Space for Ecosystem Services: A Taxonomy of Plural Values and Valuation Methods. Environmental Values, The White Horse Press, n. 27, p. 29-53, 2018.

ARIAS-ARÉVALO, P.; MARTÍN-LÓPEZ, B.; GÓMEZ-BAGGETHUN, E. Exploring Intrinsic, Instrumental, and Relational Values for Sustainable Management of Social-Ecological Systems. Ecology and Society, v.22, n. 4, p.43, 2017.

BALVANERA, P.; CASTILLO, A.; LAZOS, E.; CABALLERO, K. Marcos Conceptuales Interdisciplinarios Para El Estudio De Los Servicios Ecosistémicos En América Latina. In: LATERRA, P.;JOBBÁGY, E., et al. (Ed.). Valoración de Servicios Ecosistémicos. Conceptos, Herramientas y Aplicaciones para el Ordenamiento Territorial. Buenos Aires, Argentina: INTA, 2015. cap. 2, p. 38-67.

BATISTA, G. A. G. Biofilia Emergente como Resposta a Estresse Devido a Isolamento Social: Estudo de Caso com Estudantes Universitários. Orientador: Eliana Cardoso-Leite. Monografia (Conclusão de Curso Bacharelado em Ciências Biológicas) - UFSCar, Sorocaba, 2021.

BLANCO, J.; SOURDRIL, A.; DECONCHAT, M.; BARNAUD, C.; SAN CRISTOBAL, M.; ANDRIEU, E. How farmers feel about trees: Perceptions of ecosystem services and disservices associated with rural forests in southwestern France. Ecosystem Services, v.42, 2020.

BOITUVA 1. Conheça a história de Boituva. Município de Interesse Turístico. 2018. Disponível em: <https://www.boituva.sp.gov.br/post/conheca-a-historia-deboituva-municipio-de-interesse-turistico \$73773 >. Acesso em: 02 set. 2020. 
BOITUVA 2. Câmara dos Deputados discute título de "Capital Nacional do Paraquedismo" para Boituva. Município de Interesse Turístico. 2020. Disponível em: <https://www.boituva.sp.gov.br/post/camara-dos-deputados-discute-titulo-de\%E2\%80\%9Ccapital-nacional-do-paraquedismo\%E2\%80\%9D-paraboituva $\$ 132444$ >. Acesso em: 02 set. 2020.

BOITUVA 3. Parques são opções de lazer no feriado de Carnaval. Prefeitura Municipal de Boituva, 2020. Disponível em: <https://www.boituva.sp.gov.br/imprensa/noticias/parques-sao-opcoes-de-lazerno-feriado-de-carnaval-72933 >. Acesso em: 08 de jul. 2021.

BOITUVA 4. Parque Ecológico Recebe Visita de Crianças da Rede Municipal Através do Projeto Ama. Prefeitura Municipal de Boituva, 2019. Disponível em: $<$ https://www.boituva.sp.gov.br/imprensa/noticias/parque-ecologico-recebe-visitade-criancas-da-rede-municipal-atraves-do-projeto-ama-38962>. Acesso em: 08 de jul. 2021.

BRASIL - MMA. Ministério do Meio Ambiente. Instrução Normativa MMA nํㅡ 2, de 5 de maio de 2014. Cadastro Ambiental Rural. 2014. Disponível em: $<$ https://www.car.gov.br/\#/>. Acesso em: 02 nov. 2020

BRASIL- MMA. Ministério do Meio Ambiente. Roteiro para criação de unidades de conservação municipais [recurso eletrônico] / Ministério do Meio Ambiente, Secretaria de Biodiversidade, Departamento de Áreas protegidas - Brasília, DF: MMA, 2019.

BRUMATTI, P.N.; SANTANA, C.M.; DANTAS, F.R.; MARQUES-JUNIOR, S. Percepção de estudantes quanto aos impactos na criação e visitação de parques naturais protegidos. Revista Brasileira de Ecoturismo, São Paulo, v.11, n.4, ago2018/jan2019, p.673-694, 2019.

CARDOSO, C. A "invenção" dos espaços protegidos: a criação de parques, reservas, áreas de proteção e o conflito com a população tradicional. Revista de geografia UFPE, 2010. Disponível em: $<$ https://periodicos.ufpe.br/revistas/revistageografia/article/viewFile/228834/23244 >. Acesso em: 29 jun. 2020

CARDOSO-LEITE, E., ARRUDA, E.M., VALENTE, R.A. Relatório Final do Projeto "PAePAC- Planejamento Ambiental e Priorização de Áreas para Conservação". Parceria UFSCar - Prefeitura Municipal de Boituva. 131 pg. 2020. Disponível em: <www.ppgsga.ufscar.br/ relatorios-tecnicos-e-outras-producoes-1> CAVALCANTI, C. Sustentabilidade: mantra ou escolha moral? Uma abordagem ecológico-econômica. Estudos Avançados, São Paulo, v. 26, n. 74, 2012.

CHAN, K. M. A.; GUERRY, A. D.; BALVANERA, P.; KLAIN, S.; SATTERFIELD, T.; BASURTO, X.; BOSTROM, A.; CHUENPAGDEE, R.; GOULD, R.; HALPERN, B. S.; HANNAHS, N.; LEVINE, J.; NORTON, B.; RUCKELSHAUS, M.; RUSSELL, R.; TAM, J.; WOODSIDE, U. Ecosystem Services? A Framework for Constructive Engagement. BioScience, v. 62, n. 8, p. 744-756, 2012.

COLLEY, K.; CRAIG, T. Natural places: perceptions of wildness and attachment to local greenspace. Journal of Environmental Psychology, Aberdeen, v. 61, p. 71-78, 2019. 
COSTA, D.; NARDELLI, R. Criados critérios de classificação do espaço urbano e rural. Agência Senado. Brasília, DF. 2009. Disponível em $<$ https://www12.senado.leg.br/noticias/materias/2009/10/06/criados-criterios-declassificacao-do-espaco-urbano-erural\#: :text=\%2D\%20De\%20m\%C3\%A9dio\%20porte\%2C\%20se\%20tiver,superi or\%20a\%20cem\%20mil\%20habitantes>. Acesso em 3 de mar. De 2021.

COSTANZA, R., DE GROOT, D., BRAAT, L., KUBISZEWSKI, I., FIORAMONTI, L., SUTTON, P., FARBER, S., \& GRASSO, M. Twenty years of ecosystem services: How far have we come and how far do we still need to go? Ecosystem Services, v.28, p.1-16, 2017.

COSTANZA, R.; D'ARGE, R.; DE GROOT, R.; FARBER, S.; GRASSO, M.; HANNON, B.; LIMBURG, K.; NAEEM, S.; O'NEILL, R. V.; PARUELO, J.; RASKIN, R. G.; SUTTON, P.; BELT, M. van den. The value of the world's ecosystem services and natural capital. Nature I, v. 387, p. 253-260,1997.

DE GROOT, R. S.; ALKEMADE, R.; BRAAT, L.; HEIN, L.; WILLEMEN, L. Challenges in integrating the concept of ecosystem services and values in landscape planning, management and decision making. Ecological Complexity, n. 7, p. 260-272, 2010.

DE GROOT, R. S.; WILSON, M. A.; BOUMANS, R. M. J. A typology for the classification, description and valuation of ecosystem functions, goods and services. Ecological Economics, n. 41, p. 393-408, 2002.

DICTORO, V.P.; GALVÃO, D. F.; HANAI, F.Y. O Estudo Das Representações Sociais E Da Percepção Ambiental Como Instrumentos De Análise Das Relações Humanas Com A Ảgua. Ambiente \& Educação - Revista de Educação Ambiental, n1, v. 21, 2016.

ELLIS, E. C. Ecology in an Anthropogenic Biosphere. Ecol Monogr, v. 85, p. 287331, 2015.

ELMQVIST, T.; SETA" LA", H.; HANDEL, S.N.; VAN DER PLOEG, S.; ARONSON, J.; BLIGNAUT, J. N.; GO' MEZ-BAGGETHUN, E.; NOWAK, D. J.; KRONENBERG, J.; DE GROOT, R. Benefits of restoring ecosystem services in urban areas. Current Opinion in Environmental Sustainability, n. 14, p.101108, 2015.

FRANÇA, D. P. S.; ANDRADE, M. N. M. M.; FEITOSA, A. A. F. M. A. Parques urbanos, seus valores ecológicos e socioculturais: estudo de caso no parque zoobotânico Arruda Câmara, em João Pessoa-PB. Anais do Congresso Brasileiro de Gestão Ambiental e Sustentabilidade, CONGESTAS, v. 5, 2017. Disponível em: http://eventos.ecogestaobrasil.net/congestas/ Acesso em: 29 jun. 2020

FREITAS, W. R. S.; JABBOUR, C. J. C. Utilizando Estudo De Caso(S) Como Estratégia De Pesquisa Qualitativa: Boas Práticas E Sugestões. Estudo \& Debate, Lajeado, v. 18, n. 2, p. 07-22, 2011.

GIL, A. C. Como Elaborar Projetos de Pesquisa. São Paulo: Atlas, 2009.

GIL, N; L. P.; ROSA, M. D. A percepção ambiental acerca do Parque Estadual Serra Furada em docentes de uma escola pública de Grão-Pará. Revista eletrônica do Mestrado em Educação Ambiental - FURG, n. 1, v. 22, 2017.

IBGE 1 - Instituto Brasileiro de Geografia e Estatística. Cidades. 2020. Disponível em: <https://cidades.ibge.gov.br/brasil/sp/boituva/panorama>. Acesso em: 02 set. 2020. 
IBGE 2 - Instituto Brasileiro de Geografia e Estatística. PNAD Contínua 2019: rendimento do $1 \%$ que ganha mais equivale a 33,7 vezes o da metade da população que ganha menos. Agencia de Notícias, Estatísticas Sociais. $2020 . \quad$ Disponível em: $<$ https://agenciadenoticias.ibge.gov.br/agencia-sala-de-imprensa/2013agencia-de-noticias/releases/27594-pnad-continua-2019-rendimento-do-1que-ganha-mais-equivale-a-33-7-vezes-o-da-metade-da-populacao-queganhamenos\#: : :text=0\%20rendimento\%20m\%C3\%A9dio\%20mensal\%20real\%20 domiciliar\%20per\%20capita\%20foi\%20de,maior\%20(R\%24\%201.720)>. Acesso em 10 de mai. de 2021.

INGOLD, T. The Perception of the environment: essays in livelihood, dwelling and s kill. London and New York: Routledge, Taylor \& Francis Group, 2000.

IPBES. Repository Documentation. 2020. Disponível em: www.ipbes.net Acesso em 10 de ago. de 2020.

JOLY C. A.; SCARANO, F. R.; SEIXAS, C. S.; METZGER, J.P.; OMETTO, J. P.; BUSTAMANTE, M. M. C.; PADGURSCHI, M. C. G.; PIRES, A. P. F.; CASTRO, P. F. D.; GADDA, T.; TOLEDO, P. 10diagnóstico brasileiro de biodiversidade e serviços ecossistêmicos, 2019. Disponível em: <bpbes.net.br/wpcontent/uploads/2019/09/BPBES Completo VF-1.pdf>. Acesso em: 20 out. 2019.

KOSANIC, A.; PETZOLD, J. A Systematic review of cultural ecosystem services and human wellbeing. Ecosystem Services, 45, 2020.

LIRA, N. A.; PELICICE, F. M. Percepção dos serviços ambientais gerados por uma área natural de alto valor turístico: Cachoeira do Roncadeira (TO). Revista Brasileira de Ecoturismo, v.13, n. 3, p. 556-571,

MAMEDE, S.; BENITES, M.; SABINO, J.; ALHO, C.J.R. Ecoturismo na região turística Caminho dos Ipês: conexões entre identidade biofílica e usufruto dos serviços ecossistêmicos. Revista Brasileira de Ecoturismo, São Paulo, v.10, n.4, nov 2017/jan, p.938-957, 2018.

MEA - MILLENNIUM ECOSYSTEM ASSESSMENT. Ecosystems and Human Well-Being: Synthesis. Island Press, Washington, DC, 2005.

MELO, M. R.S.; GUEDES, N. M. R.; SOUZA, C. C. Percepção e valoração ambiental do Parque Estadual Matas do Segredo em Campo Grande, Mato Grosso do Sul. Revista Brasileira de Geografia Física, v. 9, n. 5, 2016.

MOMM-SCHULT, S. I.; FREITAS, S. R., PASSARELLI, S. H. Uso urbano e serviços ecossistêmicos em áreas protegidas: o caso do Parque Guaraciaba em Santo André (SP). Anais do III seminário nacional sobre tratamento de áreas de preservação permanente em meio urbano e restrição ambiental ao parcelamento do solo. Belém: UFPA, 2014.

MOTA, M.T.; CARDOSO-LEITE, E.; SOLA, F.; MELLO, K. Categorização da infraestrutura verde do município Sorocaba (SP) para criação de um sistema municipal integrando espaços livres e áreas protegidas. RBCIAMB, v.41, p. 122140, 2016. Disponível em: rbciamb.com.br Acesso em: 10 set. 2020.

NASCIMENTO, A. P. B.; RÉGIS, M. M.; SOBRAL, K. G. B. Serviços ecossistêmicos e percepção ambiental para estudos de parques urbanos. Gestão, percepção e uso de espaços públicos, 1 edição. Tupã: ANAP,161 p., 2019. 
OLIVEIRA JUNIOR, A. F.; COSTA, T. P.P.; TAFURI, A. C. Valoração contingente dos serviços ecossistêmicos providos pelo Parque Estadual do Itacolomi, MG. Informe Agropecuário, Belo Horizonte, v. 33, n. 271, p.108-115, nov./dez. 2012.

ONU. CÚPULA DAS NAÇÕES UNIDAS SOBRE O DESENVOLVIMENTO SUSTENTÁVEL. Transformar nosso mundo para as Pessoas e o Planeta. 2005. Disponível em: <https://nacoesunidas.org/pos2015/>. Acesso em: 20 out. 2019.

OPHULS, W. A Vingança de Platão: política na era da ecologia. São Paulo: Edições SESC São Paulo, 264 p. 2011.

OSTÓIC, S. K.; MARIN, A. M.; KICIC, M.; VULETIC, D. Qualitative Exploration of Perception and Use of Cultural Ecosystem Services from Tree- Based Urban Green Space in the City of Zagreb ( Croatia).(Article)(Report). Forests, 11, n. 8, p. 1cl, 2020.

PANASOLO, A.; GALVÃO, F.; HIGACHI, H. Y.; OLIVEIRA, E. B.; CAMPOS, F.; WROBLEWSKI, C. A. PERCEPÇÃO DOS SERVIÇOS ECOSSISTÊMICOS DE ÁREAS VERDES URBANAS DE CURITIBA/PR. BIOFIX Scientific Journal, Curitiba, v. 4, n. 1, p. 70-80, 2019.

PEIXOTO-GIACON, V. Relação entre urbanização e integridade biótica de florestas nativas. Dissertação (Mestrado Profissional em Sustentabilidade na Gestão Ambiental) - Universidade de São Carlos, campus Sorocaba, Sorocaba, 2019. Disponível em: <http://www.ppgsga.ufscar.br/alunos/banco-dedissertacoes/VanessaPeixotoGiacon.pdf/view>. Acesso em: 11 jun. 2021

PEREIRA, H.S.; KUDO, S. A.; SILVA, S. C. P. Topofilia e valoração ambiental de fragmentos florestais urbanos em uma cidade amazônica. Ambiente \& Sociedade, São Paulo, v. 21, n. 0, 2018.

RUSSELL, R.; GUERRY, A. D.; BALVANERA, P.; GOULD, R. K.; BASURTO, X.; CHAN, K.M.A.; KLAIN, S.; LEVINE, J.; TAM, J. Humans and Nature: How Knowing and Experiencing Nature Affect Well-Being. The Annual Review of Environment and Resources, v. 38, p 473-502, 2013.

SANTOS, M. F.; FILHO, D. A. C; GOMES, C. M. B.; BARACHO, R. O. Levantamento De Serviços Ambientais Do Parque Ambiental Macambira Em Goiânia -Go, Brasil. Gestão Ambiental E Políticas Públicas. Anais do IVII ENEAMB e V Fórum Latino - Americano de Engenharia e Sustentabilidade, João Pessoa - PB, 2019.

SNUC - BRASIL- MMA. Ministério do Meio Ambiente. Lei no 9.985, de 18 de julho de 2000. SNUC - Sistema Nacional de Unidades de Conservação da Natureza. Brasília, DF: MMA, 2000.

SOUSA, R.G.; SANTOS, M.L. Percepção ambiental dos usuários da Fazenda Santa Branca Ecoturismo (APA - Ribeirão João Leite), Teresópolis (GO). Revista Brasileira de Ecoturismo, São Paulo, v. 3, n. 3, p. 460-477, 2010.

STEFFEN, W.; CRUTZEN, P. J.; MCNEILL, J. R. The anthropocene: Are humans now overwhelming the great forces of nature? Ambio, v. 36, p. 614-21, 2007.

TUAN, Y. F. Espaço e lugar: a perspectiva da experiência. São Paulo: Difel, 250p., 1983.

TUAN, Y. F. Topofilia: um estudo da percepção, atitudes e valores do meio ambiente. São Paulo: Difel, 288p., 1980. 
UJHÁZY, N.; MOLNÁR, Z.; BEDE-FAZEKAS, À.; SZABÓ, M. O.; BIRÓ, M. Do Farmers And Conservationists Perceive Landscape Changes Differently? Ecology and Society, v. 25, n. 3, 2020.

VIEIRA, V. B.; GÂNDARA, J. M. G. A gestão pública municipal no desenvolvimento do turismo nas áreas naturais protegidas de Joinville (SC). Revista Brasileira de Ecoturismo, São Paulo, v.8, n.1, p.134-158, 2015.

WILLIAMS, M.; ZALASIEWICZ, J.; HAFF, P. K.; SCHWÄGERL, C.; BARNOSKY, A. D.; ELLIS, E. C. The anthropocene biosphere. Anthropology, v. 2, p. 196-219, 2015.

Agradecimentos: Agradecemos o apoio da secretaria de Planejamento Urbano e Meio Ambiente do Município de Boituva; a Escola Educativa de Dança "Isadora Duncan" pela impressão dos formulários e termos de consentimento; a Tatiana Mariano, Valéria Letícia Marques Barbosa e Jennifer Rhayra Pires de Campos pelo auxílio com entrevistas, gráficos e traduções; e a todas as pessoas que gentilmente consentiram a entrevista.

Giovana Francesca Rodrigues Consorti: : Universidade Federal de São Carlos, Sorocaba, SP, Brasil.

E-mail: gfrconsorti@hotmail.com

Link para o currículo Lattes: http://lattes.cnpq.br/7217790310517943

Gabriel Telo Mariano: Universidade Federal de São Carlos, Sorocaba, SP, Brasil.

E-mail: gabrieltelo.gt@gmail.com

Link para o currículum Lattes: http://lattes.cnpq.br/0516268891072070

Helbert Medeiros Prado: Universidade Federal de São Carlos, Sorocaba, SP, Brasil.

E-mail: helbertmedeirosprado@gmail.com

Link para o currículum Lattes: http://lattes.cnpq.br/7266995448306223

Eliana Cardoso-Leite: Universidade Federal de São Carlos, Sorocaba, SP, Brasil.

E-mail: eliana.leite@ufscar.br

Link para o currículum Lattes: http://lattes.cnpq.br/2186623269243747 